\title{
AS RELAÇÕES ENTRE A QUALIDADE DA INTERAÇÃO MÃE- CRIANÇA E O RECONHECIMENTO DA IMAGEM DE SI EM CRIANÇAS COM AUTISMO
}

\author{
THE RELATIONSHIPS BETWEEN THE CHILD- MOTHER AND SELF \\ RECOGNITION IN CHILDREN WITH AND WITHOUT AUTISM
}

Francesca Osório Di Napoli*

Cleonice Alves Bosa**

Napoli FOD, Bosa CA. As relações entre a qualidade da interação mãe-criança e o reconhecimento da imagem de si em crianças com autismo. Rev Bras Cresc Desenv Hum 2005; 15(3):11-25.

\begin{abstract}
Resumo: Este estudo examinou as relações entre os comportamentos interativos mãe-criança e o reconhecimento da imagem de si em crianças com e sem autismo A revisão teórica aponta para a importância da qualidade da interação para a emergência desta habilidade. Além disso, os estudos nessa área apontam divergências no aparecimento dessa capacidade, no que se refere a idade desenvolvimental e formas de expressão em populações atípicas. Contudo, a investigação da relação entre interação mãe-criança e reconhecimento da imagem de si raramente foi investigada. Participaram do estudo 20 díades mãe-criança distribuídas em dois grupos: desenvolvimento típico (DT), com idades entre 2e 3 anos, e autismo, com idades entre 4 e 6 anos. Foram realizadas entrevistas com as mães e uma sessão de brinquedo livre, além da técnica do espelho, replicada de estudos anteriores, para mensurar o comportamento de reconhecimento da imagem de si. As informações sobre os dados sócio-demográficos e de desenvolvimento da criança, contidas nas entrevistas realizadas com as mães, foram utilizadas na caracterização da amostra. Os vídeos das sessões de observação foram utilizados para codificação dos comportamentos maternos e infantis. Os resultados mostraram uma relação de significância entre o comportamento materno de compartilhamento de tópico e o reconhecimento da imagem de si. Também foram encontradas diferenças significativas entre os grupos quanto ao comportamento infantil de atenção compartilhada, com o grupo com DT apresentando uma freqüência maior deste comportamento que o grupo com autismo. Os resultados sugerem a importância da presença da mãe no reconhecimento da imagem de si em crianças com autismo, visto que não houve diferença significativa entre os grupos. Finalmente, ressalta-se que o exame da habilidade de reconhecimento da imagem de si, de forma independente da fala, pode ser uma ferramenta importante na avaliação psicológica de crianças com atrasos e/ou comprometimentos significativos de linguagem.
\end{abstract}

Palavras-chave: Autismo. Desenvolvimento típico. Self. Auto-reconhecimento.

\section{INTRODUÇÃO}

O auto-reconhecimento diz respeito à imagem que o indivíduo tem de si, e inclui uma seqüência e uma dinâmica. Os bebês, antes dos 9 meses de idade, parecem desconhecer to- talmente alguma relação entre eles e a sua imagem no espelho, mesmo que possam sorrir ou mover-se ${ }^{1}$. Em torno dos 9 meses, a criança começa a demonstrar sinais de auto-reconhecimento e inicia esse processo através dos toques no próprio corpo, enquanto olha a ima-

\footnotetext{
Psicóloga, Universidade Federal do Rio Grande do Sul Depto. Psicologia do Desenvolvimento. Endereço para correspondência: Instituto de Psicologia/UFRGS, Rua Ramiro Barcelos 2600, sala 110, Porto Alegre, RS, 90035003.

** Psicóloga, Universidade Federal do Rio Grande do Sul Depto. Psicologia
} 
gem. Na área de estudo com animais, Gallup ${ }^{2}$ foi pioneiro nas pesquisas envolvendo o reconhecimento da imagem de si, ao realizar um estudo com chimpanzés, comparando um grupo criado em isolamento e outro com experiências sociais. Sua hipótese era de que o grupo de animais que era criado de modo isolado não teria a oportunidade de examinar o "self" do ponto de vista do outro e, conseqüentemente, não reconheceria a si próprio frente ao espelho. Após dez dias de isolamento ou de experiência social, anestesiou os animais e pintou uma de suas orelhas de vermelho e os olhos de marrom. O pesquisador encontrou uma diferença marcante no reconhecimento da imagem de si: nenhum dos animais criados em isolamento, diante da introdução do espelho demonstrou algum sinal de auto-reconhecimento. Entretanto, os chimpanzés que tiveram experiências sociais evidenciaram inúmeros sinais de reconhecimento da imagem de si (como por exemplo, tocando na orelha pintada ou nos olhos). Esse estudo mostrou que os chimpanzés têm um senso de self e que o convívio com a mesma espécie é necessário para o seu desenvolvimento.

Esse paradigma metodológico clássico tem sido usado repetidamente com crianças. Uma marca de tinta é feita no nariz das crianças sem que elas percebam. Posteriormente, as mesmas são colocadas em frente ao espelho ${ }^{3-7}$. O toque no próprio nariz é indicador de autoreconhecimento. A questão está em como as crianças fazem esse reconhecimento e o caminho que percorrem para fazer essa identificação. Para Schaeffer ${ }^{8}$, essa questão pode ser entendida justificando a presença de dois tipos de pistas que são usadas. As de contingência derivadas do fato que a imagem no espelho se move precisamente em congruência com seus próprios movimentos; e as de características, tais como as físicas, que incluem a facial e aparência corporal, que a criança passou a associar consigo. Tais comportamentos são inicialmen- te evidenciados aos 15 meses de idade e se tornam mais efetivos aos 21 meses. De qualquer modo, o que pode ser visto é o desenvolvimento do auto-reconhecimento de forma gradativa nos dois primeiros anos de vida ${ }^{3}$.

Alguns autores, como Lewis e BrooksGunn $^{5}$ e Berenthal e Fischer ${ }^{4}$, concebem o desenvolvimento da linguagem como uma das formas de evidência do reconhecimento da imagem de si. A criança aos 2 anos de idade faz uso dos termos para referir-se a si própria e é capaz de entender seu sentido tanto como seu nome (como eu, meu). O uso do eu e você também é feito corretamente, desde o início, sem trocar o seu significado, mesmo que escute outras pessoas fazerem uso desses pronomes de modo reverso. Smolock ${ }^{1}$, ao revisar os estudos que buscam identificar o reconhecimento da imagem de si, encontrou concordância em relação à importância do papel da interação social no desenvolvimento dessa habilidade. Contudo, os autores variam em relação à ênfase dada a esse aspecto. Admitindo-se a relação entre interação social, reconhecimento da imagem de si e desenvolvimento existente, a diferença estaria no foco sobre o papel do cuidador. A partir disto, infere-se que algumas crianças estão em risco quanto ao processo de desenvolvimento do reconhecimento de si.

\section{O reconhecimento da imagem de si em crianças com autismo}

O autismo tem sido freqüentemente citado como uma síndrome, cujas características envolvem a falta de autoconsciência (ou uma falha em distinguir o eu do não eu), uma inabilidade em manter uma distinção entre o self e o não sel $f^{9,10}$. A idéia de que a criança com autismo pode sofrer de um déficit básico na autoconsciência ou auto-imagem não é nova. A literatura tem sugerido que a reação atípica dessas crianças aos estímulos sensórios interferem na 
estabilidade do self. Além disso, a falha da criança na aquisição do pronome eu como referência de si também pode estar relacionada ao déficit na autoconsciência ${ }^{10}$.

Em relação ao reconhecimento da imagem de si, referem-na como um fenômeno desenvolvimental que reflete a autoconsciência e está associado com a idade mental em que se encontra a criança. De acordo com Gallup ${ }^{2}$, um déficit na interação social e na comunicação, possível no autismo, seria conseqüência de uma deficiência no autoconceito e/ou autoconsciência, que poderia ser identificada nos testes que avaliam o reconhecimento da imagem de si. Entretanto, alguns dos estudos sobre esse assunto têm demonstrado que as crianças com autismo são capazes de reconhecer sua imagem, desde que tenham alcançado a idade desenvolvimental apropriada (20 meses). Ferrari e Matthews ${ }^{10}$, ao estudarem o reconhecimento da imagem de si em um grupo de crianças com autismo e outro com desenvolvimento típico, utilizando a técnica desenvolvida primeiramente por Gallup ${ }^{2}$, encontraram que 6 das 7 crianças testadas exibiram o reconhecimento da imagem de si. Contudo, o comportamento que acompanhava as respostas frente ao espelho diferindo das outras crianças. Por exemplo, as crianças com autismo pareciam não demonstrar autoconsciência ou reações de timidez, freqüentes nas crianças do grupo com desenvolvimento típico.

A idade demonstra ser relevante para avaliar o reconhecimento da imagem de si nesses casos. Baseados na versão de Gallup², Dawson e Mckissick ${ }^{7}$ realizaram o estudo em crianças mais jovens com autismo (4-6 anos), já que essa habilidade tem sido encontrada nas crianças mais velhas. É possível que o atraso no desenvolvimento cognitivo e emocional das crianças mais novas esteja associado a esse déficit. Outro objetivo desses autores foi determinar se a aquisição da criança com autismo das habilidades sensório-moto- ras (permanência do objeto e imitação motora) está relacionada ao desenvolvimento do reconhecimento da imagem de si. Consideram que é possível que uma falha no reconhecimento da imagem de si aconteça devido a um déficit na aquisição de habilidades cognitivas necessárias para facilitar o desenvolvimento dessa capacidade.

A permanência do objeto também tem sido relacionada ao reconhecimento da imagem de $\mathrm{si}^{4,5}$. Uma criança deve ter conhecimento do self como uma entidade separada para saber que um objeto existe independentemente da percepção dele (objeto). Os autores mencionam uma associação entre a aquisição da permanência do objeto e o reconhecimento da imagem de si, mas não encontram essa mesma relação entre o reconhecimento da imagem de si e a imitação. Os resultados da pesquisa de Dawson e Mckissick ${ }^{7}$ demonstraram que 11 das 15 crianças com autismo exibiram o reconhecimento da imagem de si. Além disso, os autores sugeriram que as crianças com autismo não mostram déficits específicos nessa habilidade, considerando inclusive a idade menor da população pesquisada. Os déficits relativamente severos na imitação motora e na linguagem contrastam com as habilidades desenvolvidas na permanência do objeto e no reconhecimento da imagem de si. Com isso, consideram provável que a possível deficiência no reconhecimento da imagem de si, evidenciada por crianças com autismo, deva-se a uma deficiência mental global e não a uma característica específica do autismo. Segundo o estudo, as crianças com autismo apresentam um número menor de vocalizações (falam com menor freqüência e apresentam um vocabulário pobre) em relação às outras e tendem a tocarem-se mais. Sobre a questão envolvendo o toque, os autores referem o fato da criança com autismo demonstrar, frente ao espelho, a necessidade de tocar em seu corpo ou no espelho para reconhecer a imagem refletida. 
Stefanik et al. ${ }^{+}$ao estudarem o reconhecimento da imagem de si em 14 crianças com autismo, encontraram que elas são capazes de reconhecerem a si em frente ao espelho quando alcançam a idade desenvolvimental crucial (18 meses). As autoras argumentam que o reconhecimento da imagem de si necessita da representação de um conceito de corpo, ou seja, da consciência do próprio corpo e de sua individualidade - um processo que se desenvolve a partir da interação social e que a questão da consciência vinculada a esse conceito, está além das limitações da investigação empírica.

Com base nas idéias acerca da trajetória da criança da construção de suas interações e do reconhecimento do self, torna-se importante pensar acerca de como isso ocorre em crianças com autismo, uma vez que exibem expressões faciais pobres. Isso dificulta o desenvolvimento da capacidade do bebê e de seus cuidadores em iniciar os reconhecimentos e processos de interação. Ao mesmo tempo, Capps et al. ${ }^{11}$ colocam que o desenvolvimento de indivíduos com autismo é caracterizado por déficits na comunicação e na interação social, o que não significa que não se engajam e respondam a interações sociais. Inúmeros fatores podem alterar a interação social da criança com autismo, como por exemplo, o nível global de desenvolvimento e o tipo de contexto no qual a interação ocorre ${ }^{11,12}$. Essa observação foi confirmada por um estudo de Bosa ${ }^{13}$, que buscou investigar experimentalmente a influência desses fatores no comportamento sócio-comunicativo de crianças pré-escolares com autismo. A autora encontrou uma freqüência de atenção compartilhada significativamente menor no grupo com autismo e sua variação dependeu do contexto e do desenvolvimento global da criança.

Amsterdam $^{3}$ e Lewis e Brooks-Gunn ${ }^{5}$ referem a questão do reconhecimento da imagem de si como dependente de um processo de construção e posteriormente de diferenciação do self, que tem seu início nos primeiros contatos mãe-bebê. Considerando que a criança com autismo apresenta uma falha nessa habilidade, é possível pensar que ela possa apresentar uma menor freqüência de episódios de atenção compartilhada, o que provocaria diferenças qualitativas no desenvolvimento do self e no reconhecimento da imagem de si. Esses resultados apontam para a importância da qualidade da interação cuidador-criança no desenvolvimento social de crianças com autismo, em especial para a consciência de si mesmo. Contudo, observa-se que a relação entre reconhecimento da imagem de si e interação mãe-criança tem recebido pouca investigação empírica, apesar da relevância teórica. Os estudos encontrados por Lewis e Brooks-Gunn ${ }^{5,6}$ não investigam a relação entre a qualidade da interação e o reconhecimento da imagem de si, enfatizando a questão da construção do self apenas teoricamente.

A qualidade da interação mãe-criança e sua importância no desenvolvimento infantil tem sido o foco de vários estudos ${ }^{14-16}$. Um dos fatores de maior importância na teoria do apego, por exemplo, refere-se à tendência "inata" dos cuidados maternos, que leva a uma responsividade básica à aparência física, comunicação e sinais de desamparo emitidos pelo bebê ${ }^{17}$. Como o desenvolvimento humano ocorre dentro de um contexto social, conforme Fitzgerald e Field ${ }^{18}$, torna-se importante considerar entre os aspectos interacionais investigados a questão da reciprocidade. O termo reciprocidade refere-se ao modo como cada parceiro recebe os sinais do outro e à maneira como responde a esses sinais. Conforme a literatura ${ }^{19}$ uma mãe sensível às mu-

Stefanik K, Balázs A, Gyori M. Mirror self-recognition in children with autism: empirical findings and theoretical considerations. $8^{\text {th }}$ European Conference on Developmental Psychology; 1997; Rennes (FR). 
danças na disponibilidade do bebê para estar em interação consegue adaptar seus comportamentos ao ritmo da criança, contribuindo para o alcance de um ajuste, entendido como sincrônico. Acredita-se que perturbações na reciprocidade podem acarretar uma interação negativa entre a díade mãe-bebê, o que poderia afetar também o desenvolvimento da atenção compartilhada. No que diz respeito ao autismo, a literatura aponta que a habilidade da atenção compartilhada encontra-se comprometida ${ }^{19,20}$.

Neste estudo, busca-se examinar a possível ocorrência de reconhecimento da imagem de si e suas possíveis relações com a qualidade da interação mãe-criança, em crianças com autismo. Outro aspecto que merece ser destacado é a metodologia empregada nos estudos referentes ao reconhecimento da imagem de si nesta população. Na maioria, o contexto interativo utilizado era entre a criança e o experimentador. Nesses estudos, o experimentador fazia uma marca com tinta no nariz da criança e em seguida colocava a criança em frente ao espelho. A evidência de reconhecimento da imagem de si se dava quando a criança tocava o próprio nariz. Contudo, considerando a forma mecânica e descontextualizada dessa metodologia, torna-se difícil atribuir a ausência do toque a uma falta de reconhecimento da imagem de si. Por exemplo, as respostas qualitativamente bizarras, encontradas em alguns estudos ${ }^{7,21}$ poderiam ser explicadas por uma desorganização geral da criança frente a uma situação nãofamiliar a ela e não necessariamente à falha no reconhecimento. Não se sabe se a presença da mãe e um contexto familiar facilitam ou não a ocorrência dessa habilidade e a qualidade da sua expressão. Em função disso, torna-se imperativo que se investigue essas questões em contextos que levem em conta os padrões de interação cuidador-criança. Finalmente, a investigação sobre a habilidade de reconhecimento da imagem de si de forma independente da fala, possui implicações clínicas importantes para a avaliação psicológica de crianças com atrasos e/ou comprometimentos significativos de linguagem, pois fornece informações sobre o desenvolvimento, inacessíveis pela expressão verbal.

O objetivo desse estudo é investigar o reconhecimento da imagem de si em crianças com e sem autismo e sua possível associação com os comportamentos maternos. Com base na revisão da literatura, espera-se que haja uma associação entre a habilidade de reconhecimento da imagem de si e a freqüência de episódios interativos entre a mãe e a criança. A qualidade dos episódios interativos também foi investigada nesse estudo.

\section{MÉTODO}

\section{Participantes}

Dez meninos com diagnóstico de autismo com base nos critérios do CID - 10 e DSM - IV e 10 crianças com desenvolvimento típico, e suas mães biológicas, participaram deste estudo. Os meninos com autismo têm idades entre 4 e 6 anos $\left(m=57,73^{++}\right.$; .dp=7,78.). Os meninos com desenvolvimento típico têm idades entre 2-3 anos $(m=26,6$; $d p=4,03$. $)$. Essa faixa etária foi escolhida em função da idade mínima onde há clara evidência de indicadores de reconhecimento da imagem de si, conforme a literatura ${ }^{1,6,14}$. As crianças de ambos os grupos apresentaram boas condições gerais de saúde e residiam com as mães biológicas, que tinham entre 20 e 35 anos.

O grupo com autismo foi recrutado em centros de atendimento a crianças com Transtornos Globais do Desenvolvimento e pré-escolas; o grupo com Desenvolvimento Típico foi selecionado em pré-escolas e centros de educa-

Idade em meses 
ção infantil. As crianças com autismo tinham o dobro da idade cronológica das crianças com desenvolvimento típico, a fim de se amenizar as discrepâncias de desenvolvimento cognitivo entre os dois grupos, uma vez que $70 \%$ das crianças com autismo possuem deficiência mental. Como não se avaliou as crianças com testes padronizados procurou-se minimizar as diferenças no nível cognitivo dos dois grupos, desta forma.

Através dos levantamentos das fichas preenchidas pelos participantes, foi possível realizar uma caracterização da população pesquisada. No que se refere ao tipo de escola verificou-se que todos os participantes do grupo com autismo (AUT) e com desenvolvimento típico (DT) freqüentavam escola particular. Comparando-se os dados referentes à configuração familiar, observa-se que a grande maioria dos participantes do grupo com desenvolvimento típico (90\%) e do grupo o com autismo (100\%) residiam com a mãe, o pai e os irmãos. Os dados das fichas de anamnese mostraram diferenças entre os grupos com relação à gravidez e parto. Em relação ao parto, nenhuma das crianças do grupo com DT apresentou intercorrências e o apgar do grupo variou entre 8 e 10. No grupo AUT, 30\% das crianças apresentaram problemas, como por exemplo, apatia, prematuridade, doenças infecciosas, etc. O apgar do grupo com AUT foi mais baixo, ficando entre 5 e 9 (média 7,5). Os grupos diferiram quanto ao choro, pois no grupo com DT as crianças, de acordo com a descrição das mães, choravam em situações não familiares, de estresse, fome, etc. No grupo com AUT as mães referiram a presença de apatia e uma importante e quase contínua irritabilidade da criança, externalizada através do choro freqüente.

\section{Instrumentos}

Os instrumentos incluíram o preenchimento do Consentimento livre e esclarecido; a Entrevista de Dados Demográficos da Família, de Desenvolvimento e Saúde da Criança (adaptada de Bosa ${ }^{13}$ ), para caracterização da amostra; um inventário de palavras, especialmente elaborado para este estudo, com base no estudo de Bates et al. ${ }^{19}$ preenchido pela mãe, através do qual se buscou investigar o número de palavras que a criança fala e/ou compreende. Este instrumento é composto de 17 categorias de palavras: comidas, brinquedos, ambiente, animais, partes do corpo, lugares, ações, veículos, modificadores, pessoas, roupas, casa, objetos, peças da casa, solicitações, saudações e outros, e foi utilizado para emparelhar os dois grupos quanto a essa habilidade. Utilizou-se o experimento de Reconhecimento da imagem de si (adaptado de Stefanik et al. ${ }^{3}$ ) que consistia na reação diante do espelho; uma sessão de 20 minutos de brinquedo livre foi utilizada para eliciar comportamentos sociocomunicativos infantis e maternos e avaliar o reconhecimento da imagem de si.

O protocolo de registro da observação envolveu a codificação por episódios de atividades conjuntas entre mãe e criança, ao invés da codificação por intervalos. Atividade Conjunta foi definida como episódios interativos onde mãe e criança estavam envolvidos com o(s) mesmo(s) objeto(s) ou ação. Desta forma, pôde-se apreender a fluência e a qualidade da interação da díade e não comportamentos maternos e infantis isolados. Os episódios tinham seu início quando a criança dirigia-se ao parceiro para a realização de uma atividade e terminava quando o foco de interesse mudava para outro objeto ou evento, registrando-se o tempo de início e término da cada episódio em minutos e segundos. Após a identificação do episódio, realizou-se a transcrição detalhada dos comportamentos maternos e infantis durante os episódios (gestos, falas e ações das díades), desconsiderando os primeiros minutos filmados, por questões de ambientação da díade. 
Para o processo de codificação foram criadas legendas para cada subcategoria das categorias maternas e infantis com objetivo de tornar as legendas mais claras. A configuração das mesmas foi feita em cores e fontes diferentes ${ }^{\#}$. Para a quantificação dos comportamentos, calculou-se o total de comportamentos maternos e infantis. Essa sessão foi realizada no laboratório de observação da universidade. O laboratório foi mobiliado com uma cadeira, almofadas e uma caixa de brinquedos dispostos sobre um tapete e um espelho fixo na parede. Os brinquedos foram escolhidos de acordo com a faixa etária dos participantes.

O comportamento materno Compartilhamento de Tópico foi definido como os comportamentos verbais e não-verbais para engajar a criança nas atividades (Repetição, Expansão, Comentário, Pergunta e Resposta a Pergunta; gestos com as mãos, com a cabeça e contato físico intencional entre o corpo da mãe ou partes dele e o da criança). O comportamento infantil Atenção Compartilhada incluiu orientação da cabeça/corpo e sorriso dirigido à mãe ao mesmo tempo em que mostra ou faz comentários sobre os brinquedos/eventos.

Para o levantamento dos vídeos, foram recrutados dois bolsistas “cegos” aos objetivos do estudo e que receberam treinamento quanto à codificação dos comportamentos maternos e infantis, de forma independente. Para a quantificação dos comportamentos, calculou-se o total de comportamentos maternos e infantis ao longo dos 3 minutos codificados. O cálculo do total de cada categoria foi obtido somando suas subcategorias. Desta forma, obteve-se índices de freqüência para a categoria materna (Compartilhamento de Tópico) e infantil (Atenção Com- partilhada).

\section{PROCEDIMENTO}

Inicialmente, agendaram-se as visitas a escolas especiais e pré-escolas infantis, sendo explicados os objetivos e procedimentos do estudo. Posteriormente, contatou-se as famílias para agendamento do encontro e para sessão de observação no laboratório da universidade. No primeiro encontro, realizou-se o preenchimento do consentimento livre e esclarecido e a entrevista de dados demográficos, assim como foi entregue o Inventário de Palavras para que a mãe preenchesse e devolvesse no dia da filmagem da díade. Na sessão de observação, a mãe após combinação prévia com a pesquisadora fazia uma mancha de tinta vermelha no nariz da criança e colocava-a diante de um espelho.

\section{RESULTADOS}

\section{Dados do Inventário de Palavras}

A média de palavras que as crianças entendiam foi de 333,5 e um desvio padrão de 15,54 no grupo com DT e de 183,8 , com desvio padrão de 95,86 no grupo 2. Quanto ao número de palavras que a criança fala, o grupo com DT apresentou média de 325,8 e desvio padrão de 19,66 enquanto que no grupo com AUT esse valor é de 119 com desvio padrão de 112,46. Os resultados do teste de MannWhitney indicam que não há uma diferença significativa entre os grupos quanto ao número de palavras que a criança entende e fala $(\mathrm{U}=1,000$, $\mathrm{p}<0,001$ para ambos), embora o vocabulário no grupo com DT seja bem mais amplo que no grupo com AUT (Figura1).

\footnotetext{
Sousa AD, Bosa C. Protocolo de registro de transcrição dos episódios de atividades conjuntos: Instituto de Psicologia - UFRGS. Porto Alegre; 2002 (Instrumento não-publicado).
} 


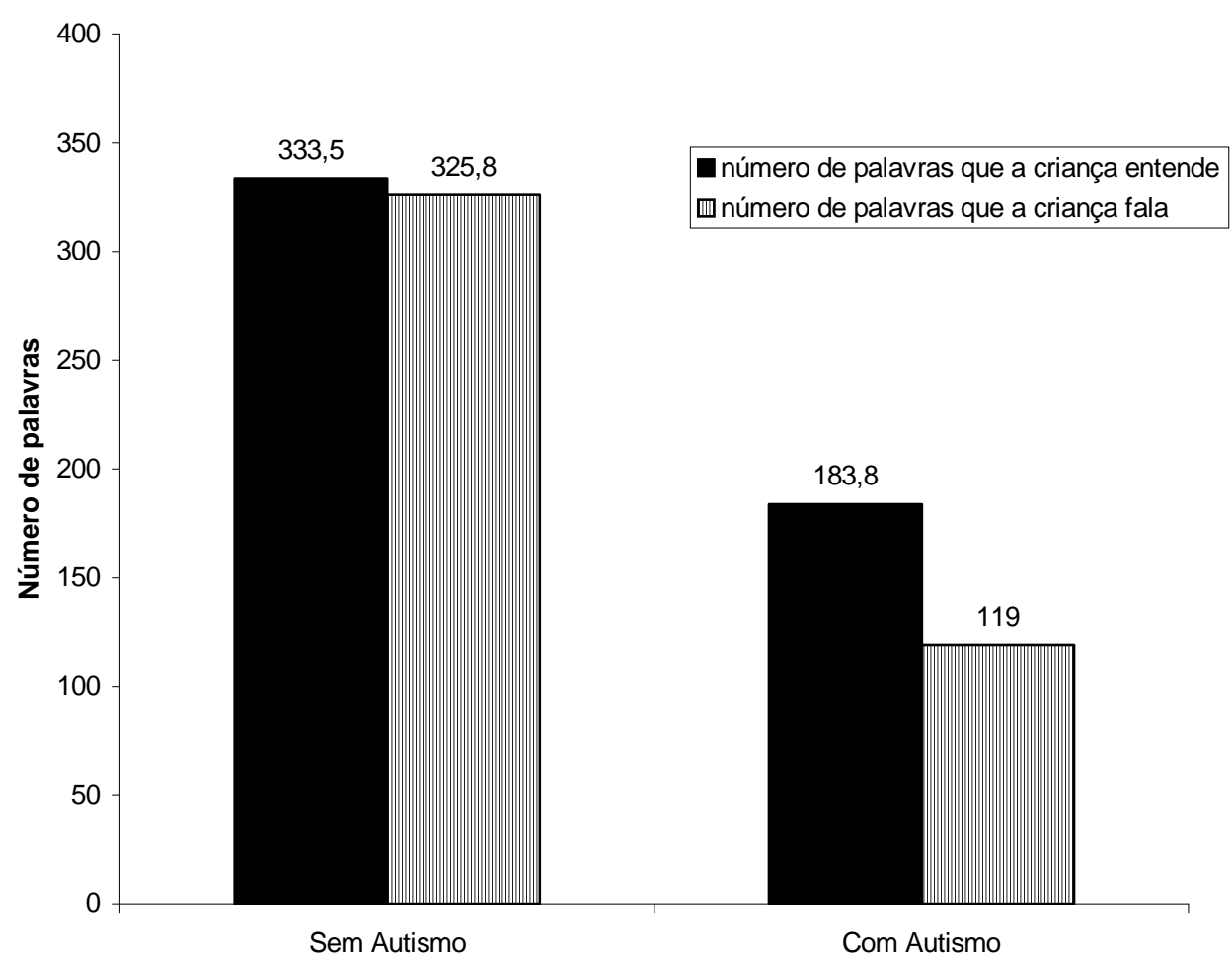

\section{Sessão de Observação}

As variáveis analisadas incluem os comportamentos maternos e infantis bem como os comportamentos de reconhecimento e não reconhecimento da imagem de si. No que diz respeito ao comportamento materno de Compartilhamento de Tópicos não foram encontradas diferenças estatisticamente significativas entre os grupos, conforme o teste de Mann-Whitney $(U=33, p=0,19)$. A freqüência do comportamento materno de Compartilhamento de Tópico foi de 200 no grupo com DT e 143 no grupo com AUT (Tabela 1), significando que apesar das mães do grupo com desenvolvimento típico terem compartilhado mais os brinquedos

Tabela 1. Médias e Desvio- padrão dos Comportamentos Maternos e Infantis

\begin{tabular}{lcc}
\hline Grupo & $\begin{array}{c}\text { Média (dp) } \\
\text { comport. Materno } \\
(\mathrm{CT})\end{array}$ & $\begin{array}{c}\text { Média (dp) } \\
\text { comport. Infantil } \\
(\mathrm{AC})\end{array}$ \\
\hline DT & $20(9,49)$ & $20,3(9,21)$ \\
AUT & $14,3(11,5)$ & $8,5(7,85)$ \\
\hline
\end{tabular}

durante a sessão de observação, essa diferença não alcançou significância estatística.

Foram encontradas diferenças significativas quanto ao comportamento infantil, onde o grupo com autismo apresentou menor freqüência de Atenção Compartilhada ( $U=13,5$; $\mathrm{p}=0,04)$ que as crianças com desenvolvimento típico como mostra a Tabela 1 . Outro dado relevante diz respeito a duração média dos episódios em ambos os grupos. Ainda que a diferença entre os grupos não seja significativa ( $\mathrm{p}=0,308$ ), o tempo médio do grupo com autismo foi menor do que no grupo com desenvolvimento típico. A média de duração de episódios observados foi 32s no grupo com DT e 42s no grupo com AUT. Quanto à média de número de episódios, este foi de 5,2 no grupo com DT e 4,9 no grupo com AUT.

\section{Reconhecimento da Imagem de Si}

Os comportamentos de reconhecimento da imagem de si foram divididos em duas grandes categorias: reconhecimento da imagem de 
si e não reconhecimento. A evidência de que houve reconhecimento da imagem de si ocorria quando a criança tocava o próprio nariz ou fazia referência a si, ao ver a sua imagem refletida no espelho.

Reconhecimento da imagem de si: comportamento identificado quando a criança apresentava evidências de duas formas: através do toque e da referência verbal a si.

Toque: tocar com a mão ou o dedo no nariz; limpar a mancha no nariz enquanto se olha no espelho. Este comportamento pode ser acompanhado das seguintes categorias de comportamentos: reações negativas - agitação corporal (movimento do corpo e braços); agressividade frente ao reconhecimento (empurra, grita chuta, joga o corpo para trás); reação positiva-risos, brincadeiras e encabulamento (baixa a cabeça frente ao reconhecimento, pode sorrir ou não).

Referência verbal a si: Inclui 2 categorias - olhar-se no espelho e se reconhecer (diz quem é); chamar atenção da mãe (aponta e chama verbalmente) para a própria imagem no espelho.

Não reconhecimento da imagem de si: A identificação desses comportamentos se deu também através de duas formas: quando a criança não toca em seu nariz e não faz referência verbal a si.

Não toca: inclui 4 categorias: evitação (a mãe mostra o espelho e a criança evita de olhar a própria imagem); agressividade(empurra o espelho, grita); choro; indiferença (não demonstra nenhuma reação ou comportamento com relação à mancha ou diante do espelho.

Não Referência verbal a si: Não diz quem é; não chama atenção da mãe ( verbalmente e/ou apontando) para a própria imagem no espelho.

As crianças do grupo com desenvolvimento típico apresentaram com unanimidade (100\%) comportamentos de reconhecimento diante da imagem no espelho. Apenas uma apresentou um número de comportamentos de reconhecimento menor do que as outras do grupo, sendo justamente a criança mais jovem do grupo. Esse resultado parece corroborar a idéia de que fatores desenvolvimentais podem estar associados a essa questão, mais especificamente, idade desenvolvimental inferior a 24 meses.

No grupo com autismo, apenas $50 \%$ das crianças apresentaram evidências de reconhecimento da imagem de si. Alguns comportamentos de reconhecimento foram identificados, mas estes apareceram quase sempre associados a reações negativas, tais como bater no espelho, lamber objetos, encostar o rosto no espelho, bater no espelho, olhar para a imagem e jogar o corpo para trás, além de estereotipias e movimentos circulares frente a imagem refletida. A Tabela 2 mostra as freqüências e as porcentagens do comportamento de reconhecimento da imagem de si nos dois grupos.

Tabela 2. Freqüência Simples e Porcentagens do Comportamento de Reconhecimento da Imagem de si

\begin{tabular}{lcc}
\hline Grupos & $\begin{array}{l}\text { Freqüência (porcentagem) } \\
\text { do comportamento de re } \\
\text { conhecimento da imagem } \\
\text { de si }\end{array}$ \\
\cline { 2 - 3 } & $f$ & $\%$ \\
\hline $\begin{array}{l}\text { Desenvolvimento } \\
\text { Típico }(n=10)\end{array}$ & 10 & 100 \\
Autismo $(n=10)$ & 5 & 50 \\
\hline
\end{tabular}

O comportamento de tocar o nariz com a mão ou o dedo foi identificado na mesma proporção nos dois grupos, o que denota que a criança ao identificar a mancha pode se tocar como resposta à percepção da tinta no nariz (gelado, molhado, denso). A categoria que descreve o limpar a mancha no nariz enquanto se olha no espelho ocorreu em $80 \%$ das crianças do grupo com desenvolvimento típico ao passo que no grupo com autismo foram apenas $40 \%$. Já a agitação corporal não ocorreu no grupo com desenvolvimento típico, sendo encontrada 
em uma criança com autismo (associada aos comportamentos de reconhecimento). A agressividade frente ao reconhecimento foi encontrada na mesma proporção no grupo com DT e com AUT (30 \%). A categoria de risos apareceu em $60 \%$ das crianças com desenvolvimento típico e em $20 \%$ do grupo com autismo. Em relação ao encabulamento, este foi encontrado em 30\% do grupo com DT e apenas em 10\% do grupo com AUT.

No que se refere ao comportamento de referência verbal, 50\% das crianças do grupo com DT se olharam e fizeram referência verbal a si, o que não foi encontrado em nenhum sujeito do grupo com AUT. Tal achado aponta para o que a literatura traz sobre a dificuldade da criança com autismo em fazer referência a si e utilizar pronomes como eu e tu. Quanto a chamar pela mãe para mostrar a imagem no espelho, $60 \%$ dos sujeitos do grupo com DT apresentaram tal evidência, enquanto que no grupo com AUT essa porcentagem caiu para $10 \%$.

No que diz respeito aos comportamentos de não reconhecimento da imagem de si, nenhuma das crianças com desenvolvimento típico apresentou comportamentos das categorias incluídas. Por outro lado, a evitação foi encontrada no grupo com AUT em $30 \%$ das crianças. A agressividade e o choro aparecerem em $10 \%$ dos casos e a indiferença, evidenciouse em $20 \%$ das situações diante do espelho nos casos de não reconhecimento.

No que tange ao comportamento de não referência verbal a si, a categoria que abrange o não se olhar no espelho e se reconhecer foi encontrada somente no grupo com AUT, onde $50 \%$ das crianças não se reconheceram. Por fim, a categoria que descreve a situação da criança não chamar a atenção da mãe para a imagem no espelho foi identificada em apenas 10\% das crianças com desenvolvimento típico e em $90 \%$ no grupo com autismo. De acordo com o teste de Mann-Whitney, não foi encontrada diferença significativa entre os grupos no que se refere ao reconhecimento da imagem de si ( $p=0,088$ ) apesar de $50 \%$ das crianças não terem se reconhecido.

Os achados apontam para a relação existente entre o comportamento materno e o reconhecimento de imagem de si. A análise de regressão linear mostrou que independente da criança ter ou não autismo, o reconhecimento da imagem de si mostrou-se associado ao comportamento materno $(\mathrm{p}<0,001 ; \mathrm{r}=0,003)$.

\section{DISCUSSÃO}

O presente estudo investigou o reconhecimento da imagem de si em crianças com e sem autismo. Além disso, também examinou a possível associação entre o reconhecimento da imagem de si e o comportamento materno. Com base na revisão da literatura, a expectativa inicial era a de encontrar evidências de reconhecimento da imagem de si em crianças com autismo, considerando a presença da mãe como facilitadora, bem como sua possível relação com a freqüência de comportamentos interativos maternos. Esperava-se também encontrar diferenças entre os grupos quanto ao comportamento de Atenção Compartilhada. Neste estudo, todas as crianças com desenvolvimento típico se reconheceram no espelho, ao passo que apenas metade das crianças com autismo o fizeram, embora esta diferença não tenha sido estatisticamente significativa. A revisão da literatura mostrou que as crianças com transtornos globais do desenvolvimento mostram seu reconhecimento através de comportamentos primitivos e bizarros ${ }^{23,5}$. De fato, no presente estudo, as crianças com autismo que se reconheceram o fizeram, em sua maioria, através de agressividade, agitação motora e estereotipias, além do toque no nariz. Mais interessante ainda foi o fato de que algumas demonstraram reconhecer objetos da sala através do espelho, mas foram 
incapazes de reconhecerem a si próprias.

As crianças com um número maior de episódios de atenção compartilhada, em sua maioria faziam parte do grupo com DT, apresentaram evidências claras de reconhecimento da imagem de si, tanto através do toque como da referência verbal, além de mostrarem-se afetivamente muito próximas de suas mães. O grupo com autismo, ao contrário, demonstrou sinais qualitativamente diferentes quanto ao desenvolvimento desta habilidade. Os comportamentos de timidez e retraimento estiveram mais presentes no grupo com DT, o que vem a corroborar estudos anteriores que referem que crianças com autismo mostram-se menos retraídas e mais agitadas, além de apresentarem menor freqüência de episódios interativos de um modo geral.

Lewis ${ }^{24}$ encontrou evidências empíricas para a hipótese de que há uma sincronia entre a emergência do self e a consciência do outro. Em um estudo transversal, os achados foram significativos quanto ao reconhecimento da imagem de si como um indicador de autoconsciência; o comportamento de autoconsciência quando o outro é centro da atenção, isto é, o comportamento empático em direção a outra pessoa, diante de uma situação de sofrimento; e a comunicação entre pares não-familiares, através de imitação sincrônica. Essas consistências foram encontradas entre os 18 e 20 meses de idade, quando metade das crianças de uma amostra com desenvolvimento típico mostrou reconhecimento de si diante da imagem no espelho.

Cabe ressaltar aqui as questões referentes ao desenvolvimento da linguagem, visto que os sinais de reconhecimento da imagem de si envolvem em sua maioria verbalizações. A criança, para se reconhecer, usa o pronome eu e tu para fazer a diferenciação diante da imagem, o que torna importante que haja um alcance em termos de desenvolvimento cognitivo para que isso possa ser mensurado. A literatura aponta existir uma dificuldade em utilizar esses pronomes nas crianças com autismo, o que torna essa população especial para investigação visto que, entre os aspectos que caracterizam o transtorno, o atraso na fala é considerado significativo e muitas vezes define o diagnóstico ${ }^{25,26}$. Isso explica, nos delineamentos de pesquisa, a escolha de crianças do grupo com desenvolvimento típico com metade da idade cronológica do grupo com autismo. Na literatura, foram encontradas evidências de reconhecimento da imagem de si em crianças com autismo, mas que tinham atingido a idade desenvolvimental do estabelecimento da habilidade, isto é, ao redor dos 24 meses. Essa questão vem corroborar os dados apurados por alguns autores, os quais também encontraram evidências do reconhecimento da imagem de si em crianças com autis$\mathrm{mo}^{4,5,27}$.

A proposta de uma possível associação entre os aspectos interacionais da díade e o reconhecimento da imagem de si podem ser melhor explorados com base nos achados que relacionam o reconhecimento da imagem de si aos comportamentos de atenção compartilhada e compartilhamento de tópico ${ }^{4,27,28}$. Se considerarmos o papel da interação na formação do self e, consequentemente, na consciência do outro, é possível pensar que a falta ou baixa freqüência interativa dificulta esse processo. É importante ressaltar que as crianças que se reconheceram no espelho apresentaram um número maior de episódios de atenção compartilhada; isto torna possível compreender que aquelas que não demonstraram sinais de reconhecimento da imagem de si não o fizeram porque provavelmente não desenvolveram na relação diádica as trocas afetivas interativas que possibilitam à criança a sua própria diferenciação.

Outro aspecto que deve ser incluído envolve o que Lewis e Brooks-Gunn ${ }^{5}$ definiram como auto-conhecimento (self-knowledge). Os autores propõem que o conhecimento do outro é desenvolvido através da interação com o mes- 
mo. Sem a interação com o mundo, haveria pouco conhecimento sobre o outro. Tais transações envolvem a criança consigo mesma e implicam na capacidade de entender que ela é diferente da outra pessoa com a qual está interagindo. É através da interação que a criança adquire conhecimento de si, tanto quanto do outro. Com isso é possível relacionar a importância da interação para o estabelecimento e desenvolvimento do selfe, consequentemente para o reconhecimento da imagem de si visto que, para haver o reconhecimento, a criança precisa identificar-se no espelho.

As diferenças entre os grupos na habilidade de reconhecimento da imagem também não podem ser atribuídas a diferenças sócioculturais, visto que a amostra contemplou crianças de nível sócio-econômico médio, com mães que tinham pelo menos o segundo grau completo (todas as mães tinham nível superior completo ou incompleto). Sobre isso, Samero$\mathrm{ff}^{28}$ refere que essas influências sociais e econômicas não afetam, necessariamente, o desenvolvimento da relação mãe-criança diretamente, mas o fazem de forma indireta. Por exemplo, se há uma situação com condições de vida precária, que cause privações e preocupações à mãe, provavelmente a criança não receberá o suporte necessário que atenda a sua demanda.

No que diz respeito aos estudos de interações mãe-bebê, houve um grande impulso a partir do reconhecimento das capacidades perceptivas e comunicativas do bebê, desde o nascimento. Trevarthen ${ }^{29,30}$, em sua teoria da intersubjetividade primária, postula que o desenvolvimento social e cognitivo da criança procede através da maturação de suas capacidades inatas.

Tais contribuições teóricas permitem a compreensão acerca da ausência de diferença significativa entre os grupos, no que diz respeito ao Compartilhamento de Tópico nas mães. Surpreendentemente, tanto as mães das crianças com desenvolvimento típico quanto as das crianças autistas tentaram compartilhar com a criança os objetos e eventos ao redor. Dentro dessa perspectiva, Bruner ${ }^{31}$ ressaltou a importância do papel materno ativo durante a interação. Denominou de scaffolding o processo que ocorre durante os jogos sociais entre a díade mãe-criança, nos quais a mãe trabalha para manter o jogo interessante, estando atenta ao nível de complexidade que o filho pode compreender. As mães das crianças com autismo buscavam a interação com o filho que, por sua vez, pouco correspondia à estimulação oferecida,, dificultando tanto o estabelecimento das trocas na interação quanto sua manutenção. $\mathrm{O}$ contexto estruturado da sessão de observação pode ter contribuído para este estilo materno de interação, em mães de crianças autistas. Por outro lado, as diferenças significativas encontradas quanto à Atenção Compartilhada nas crianças com autismo podem ser devido às limitações e comprometimentos encontrados no autismo. Ou seja, é comum o retraimento da interação - a típica retirada da criança possivelmente pelo excesso de estimulação - de acordo com Bosa ${ }^{32}$. Ainda, segundo a autora, a criança não é capaz de realizar e manter essas trocas afetivas porque não compreende a função desses atos. Essa dificuldade pode ser observada através da duração média dos episódios de AC, nos quais o grupo com autismo apresentou uma média de duração inferior, em relação ao grupo com desenvolvimento típico.

Dentro dessa perspectiva, Bruner ${ }^{31}$ afirma que a mãe, durante os jogos sociais, vai gradualmente possibilitando que, no avanço dessas atividades, a criança possa ir tomando mais iniciativa e independência. Os comportamentos de scaffolding têm como objetivo intermediar as potencialidades infantis ligadas à atenção compartilhada, ao fornecerem pistas e reforçarem a performance correta de uma tarefa. Isso pode ser constatado durante os episódios de interação da díade, pois esses comportamentos foram observados em maior freqüência no 
grupo com Desenvolvimento Típico, no qual a criança respondia aos investimentos da mãe e, com auxílio da mesma, ia se tornando mais independente, como, por exemplo, para escolher brinquedos, permanecer ou não sozinha nas brincadeiras, etc. As díades do grupo com autismo apresentaram um número menor de episódios de Atenção Compartilhada, raramente respondendo aos estímulos maternos. Esse grupo explorou, principalmente, o brinquedo musical, ao passo que o grupo com desenvolvimento típico preferiu brincar com o quebra-cabeça, a fazendinha e as brincadeiras de casinha, nos quais solicitavam a participação materna. Durante os episódios de brincadeiras, as crianças do grupo com desenvolvimento típico buscavam aprovação materna, principalmente através das trocas de olhares, enquanto que as crianças do grupo com autismo buscavam a mãe, quando precisavam alcançar algum brinquedo ou fazê-lo funcionar. Apenas duas crianças realizaram trocas de olhares com a mãe para rir e mostrar algo.

Com isso, as alterações na qualidade da interação podem ser entendidas pela perspectiva de vários autores como podendo interferir na maneira como cada parceiro social recebe os sinais do outro e na maneira como responde aos mesmos e se reconhece ${ }^{14,15,33,34}$. Torna-se imperativo discutir essas questões referentes à interação, visto que os estudos realizados acerca do reconhecimento da imagem de si em crianças não apontam a questão desta relação, empiricamente. Assim, ao investigar a possível associação do reconhecimento da imagem de si e a qua- lidade da interação da díade, encontrou-se relevância quanto aos comportamentos maternos no desenvolvimento dessa habilidade.

A proposta de uma possível associação entre os aspectos interacionais da díade e o reconhecimento da imagem de si pode ser melhor explorada a partir dos achados que relacionam o reconhecimento da imagem de si aos comportamentos maternos de compartilhamento de tópico. Ao considerarmos o papel da interação na formação do self e, consequentemente, na consciência do outro, é possível pensar nas implicações da falta ou baixa freqüência de atividade interativa para o desenvolvimento do self. Conforme mencionado, como as crianças que se reconheceram no espelho apresentaram um número maior de episódios de atenção compartilhada pode-se supor que aquelas que não demonstraram sinais de reconhecimento da imagem de si provavelmente não desenvolveram na relação diádica possibilitando à criança sua própria diferenciação.

Por fim, os achados deste estudo apontam para a necessidade de se estar atento à relação mãe-bebê, enquanto determinante para a construção do self.Aausência do reconhecimento da imagem de si pode ser entendida como decorrente de problemas no desenvolvimento do processo de interação cuidador-criança, além de apontar para a importância de aspectos maturacionais. Ao mesmo tempo, também é possível pensar que, ao menos no que se refere a esta instância do self (reconhecimento de si), crianças com autismo podem apresentar esta habilidade, ainda que a manifestem de modo bizarro.

\begin{abstract}
This study examined the relationships between the of child- mother and self -recognition in children with and without autism. More recent theories outline the quality of child-mother interactions for the emergency of this ability. It was observed that there are divergences in the emergence of that capacity, the role of the developmental age and forms of expression in atypical population However, the relationship between child-mother interaction and self recognition was rarely investigated. In this study, participated twenty child-mother dyads distributed in two groups (typical development (DT) and autism). Interviews with the mothers, a play session, and experimental techniques for measuring self recognition were used. The videos of the observation session were used for coding both the maternal and child's behaviors. Associations between the
\end{abstract}


self-recognition maternal behaviors were also found. The results showed differences between the groups on child's behaviors with the TD group showing greater frequency of joint attention. The results suggest that the presence of the mothers seems to be important for the occurrence of self-recognition. Finally, the examination of the self-recognition ability, independently of the speech, may be an important tool in the psychological assessment of children with language impairment and/or delay.

Key-words: Autism. Typical Development. Self. Self-recognition.

\section{REFERÊNCIAS}

1. Smolock L. Infancy. New Jersey (NJ): PrenticeHall; 1986.

2. Gallup GG Jr. Chimpanzees: self-recognition. Science. 1970;167:86-8.

3. Amsterdam B. Mirror self-image reaction before age two. Dev Psychobiol. 1972;5:297-305.

4. Bertenthal BI, Fischer KW. The development of self-recognition in the infant. Dev Psychol. 1978;14:44-50.

5. Lewis M, Brooks-Gunn J. Social cognition and the acquisition of self. New York (NY): Plenum; 1979.

6. Lewis M, Brooks-Gunn J. Self-knowledge and emotional development. In: Lewis M, Rosenblum $\mathrm{L}$, editors. The development of affect: the genesis of behavior. New York (NY): Plenum; 1978. p. 20526.

7. Dawson G, McKissick FC. Self recognition in autistic children. J Autism Dev Disord. 1984;14(4):383-94.

8. Schaeffer HR. Social development. Glasgow: Blackwell; 1996.

9. Bettelheim B. The empire fortess: infantile autism and the birth of the self. New York (NY): Free Press; 1967.

10. Ferrari M, Matthews W. Self-recognition deficits in autism: syndrome or general developmental delay? J Autism Dev Disord. 1983;13(3):317-24.

11. Capps L, Sigman M, Mundy P. Attachment security in children with autism. Dev Psychopathol. 1994:6:249-61.

12. Mundy P, Sigman M. Specifying the nature of the social impairment in autism. In: Dawson G, organizer. Autism: new perspectives on nature, diagnosis, and treatment. New York (NY): Guilford; 1989. p. 3-21.

13. Bosa C. Affect, social, comunication and self-stimulation in children with and without autism: a systematic observation study of re questing behaviours and joint attention [dissertation]. London: University of London, Institute of Psychiatry; 1998.

14. Brazelton TB, Cramer B, Kreisler L, Scappi R, Soulé M. A dinâmica do bebê. Porto Alegre: Ar tes Médicas; 1987.

15. Lester BM, Hoffman J, Brazelton TB. The rhyth mic structure of mother-infant interaction in term and preterm infants. Child Dev. 1985;56(1):15-27.

16. Mazet P, Stoleru S. Manual de psicopatologia do recém-nascido. Porto Alegre: Artes Médicas; 1990.

17. Grossman K, Fremma-Bombik E, Rudolph J, Grosmann K. Maternal attachment representations as related to patterns of infant mother attachment and maternal care during the first year. In: Hinde RA, Stevenson-Hinde J, editors. Relationships within families: mutual influences. Oxford: Clarendon; 1988. p. 324-79.

18. Fitzgerald HE, Field T. Depression. Infant Ment Health J. 1997;18:335-8.

19. Bates E, Camaione C, Volterra V. The acquisition of performatives prior to speech. In: Ochs E, Schieffeling B, organizers. Developmental pragmatics. London: Academic Press; 1979. p. 111-28.

20. Mundy P, Sigmann M, Ungerer JA, Sherman T. Defining the social deficits of autism: the contribution of nonverbal communication measures. J Child Psychol Psychiatry. 1986;27(5):657-69.

21. Robertson JM, Tanguay PE, L’Ecuyer S, Sims A, Waltrip C. Domains of social communication handicap in autism spectrum disorder. J Am Acad Child Adolesc Psychiatry. 1998;38(6):738-45.

22. Neuman CJ, Hill SD. Self-recognition and stimulus preference in autistic children. Dev Psychobiol. 1978;11(6):571-8.

23. Asendorpf J, Warkentin V, Baudonniére P. Selfawareness and other awareness II: mirror selfrecognition, social contingency awareness, and synchronic imitation. Dev Psychol. 1996;32:31321.

24. Lewis M. Origins of self-knowledge and 
individual differences in early self-recognition. In: Suls J, Greenwald AG, editors. Psychological perspectives on the self. Hillsdale (NJ): Erlbaum; 1986. v.3, p. 55-78.

25. Ornitz EM, Ritvo ER. The syndrome of autism: a critical review. Am J Psychiatry. 1976;133(6):609-21.

26. Rutter M. Infantile autism. In: Shaffer D, Erhardt A, Greenhill L, editors. A clinician's guide to child psychiatry. New York (NY): Free Press; 1985. p. 48-78.

27. Markus H, Cross S. Theory and research. In: Pervin LA, editor. Handbook of personality. New York(NY): Guilford; 1990. p. 577-609.

28. Sameroff AJ. Necessidades psicológicas da mãe em interações precoces mãe-filho. In: Avery G, editor. Neonatologia. Rio de Janeiro: MEDSI; 1984. p.113-187.

29. Trevarthen C. Communication and cooperation in early infancy: a description of primary intersubjectivity. In: Bulova M, organizer. Before speech: the beginnings of human communication. London: Cambridge University; 1979. p. 321-47.

30. Trevarthen C. Intrinsic motives for companionship in understanding: their origin, development, and significance for infant mental health. Infant Ment Health J. 2001;22:95-131.

31. Bruner J. Learning how to do things with words. In: Bruner J, Garton A, editors. Human growth and development. Oxford: Clarendon; 1978. p. 6284.

32. Bosa CA. As relações entre autismo, comportamento social e função executiva. Psicol Reflex Crit. 2001;14(2):281-9.

33. Brazelton TB. O desenvolvimento do apego: uma família em formação. Porto Alegre: Artes Médicas; 1988.

34. Tronick EZ, Cohn JF. Infant-mother face-to-face interaction: age and gender differences in coordination and the occurence of miscoordination. Child Dev. 1989;60(1):85-92. 